Egyptian

Orthodontic Journal

\title{
EFFECT OF NANO-HYDROXYAPATITE VERSUS CASEIN PHOSPHOPEPTIDE AMORPHOUS CALCIUM PHOSPHATE ON REMINERALIZATION OF EARLY ENAMEL LESIONS - IN VITRO STUDY
}

\author{
Yomna M. Yacout ${ }^{1}$, Mohamed I. Mowafy ${ }^{2}$, Essam M. Abdallah ${ }^{3}$
}

\section{ABSTRACT:}

Objective: To evaluate and compare the effect of zinc carbonate - nano hydroxyapatite ( $n-\mathcal{H A}$ ) (Biorepair toothpaste) and casein phosphopeptide - amorphous calcium phosphate (CPP-ACP) (GC Tooth Mousse creme) on the depth of white spot lesions (WSLs). Materials and Methods: Thirty six human premolar teeth with artificially induced WSLs were randomly assigned to three

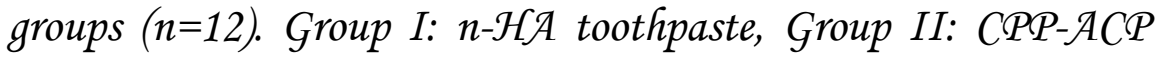
topical creme, and Group III: negative control. The teeth were longitudinally sectioned and photographed using polarized light microscopy (PLM) and the depth of enamel subsurface demineralization was measured. Statistical analysis was performed. Results: The n-HA group showed the least mean lesion dept $h$, followed by the CPP-ACP group $(76.8 \pm 10.2 \mu \mathrm{m}$ and $79.8 \pm 9.7 \mu \mathrm{m}$ respectively), while, the control group showed the largest mean lesion depth $(107.8 \pm 8.5 \mu \mathrm{m})$. The difference between the control group and each of the test groups was significant $(p<0.001)$, while there was no significant difference between the two test groups. Conclusion: Both $n-\mathcal{H}$ A and CPP-ACP showed significant remineralization of the early enamel lesions compared to the control group.

1 - Instructor, Orthodontic department, Faculty of Dentistry, Alexandria University

2 - Assistant Professor, Orthodontic department, Faculty of Dentistry, Alexandria University

3 - Professor, Orthodontic department, Faculty of Dentistry, Alexandria University 
Egyptian

Orthodontic Journal

\section{INTRODUCTION}

Fixed orthodontic appliances increase plaque accumulation in otherwise unsusceptible areas of the teeth, ${ }^{1,2}$ which elevates the level of acidogenic bacteria and thus lowers the $\mathrm{pH}$ of the oral cavity. ${ }^{3}$ This in turn favors enamel demineralization and hinders enamel remineralization resulting in the development of white spot lesions (WSLs). ${ }^{4}$

Various materials have been proposed in the literature in attempts to remineralize WSLs. Different fluoride products are used to promote enamel lesion remineralization, ${ }^{5-10}$ however, fluoride results in hypermineralization of the surface layer of the lesion thus inhibiting remineralization of the subsurface body of the lesion. ${ }^{11}$ An ideal remineralization system should promote mineral deposition in the subsurface body of the lesion rather than deposition only in the surface layer. $^{12}$

Casein phosphopeptide-amorphous calcium phosphate (CPP-ACP) has been suggested to foster remineralization of the subsurface lesions by promoting deposition of calcium and phosphate ions into the crystal voids. Reference 13 Shen et $\mathrm{al}^{14}$ and Walker et $\mathrm{al}^{15}$ demonstrated in human in situ models that CPP-ACP increases remineralization of enamel subsurface lesions in a dose-related manner. Kumar et al ${ }^{16}$ investigated the efficacy of CPP-ACP on the remineralization of enamel lesions in vitro and found that the lesion depth decreased significantly by $10.1 \%$ compared to a $7 \%$ decrease using a fluoridated toothpaste.

The use of nanotechnology currently presents a new method to remineralize early enamel lesions through the use of nano-hydroxyapatite (n-HA). ${ }^{17}$ Toothpastes containing n-HA were first researched in Japan in the late 1980s in an in vitro study ${ }^{18}$ and a 3 -year prospective clinical trial $^{19}$. Recently, studies have shown that n-HA has some potential to repair enamel owing to its chemical and structural similarity with enamel minerals. $^{20-22}$

This study was conducted to evaluate and compare the effect of n$\mathrm{HA}$ and CPP-ACP on the remineralization of initial enamel lesions in vitro. The null hypothesis was that no significant difference would be found between the two materials. 
Egyptian

Orthodontic Journal

\section{MATERIALS AND METHODS}

Thirty six premolar teeth that were extracted for orthodontic purposes were used to study the effect of n-HA and CPP-ACP on the depth of demineralized enamel lesions. The selected teeth had intact buccal enamel surfaces with no caries, decalcifications or restorations. All the teeth were thoroughly cleansed and the enamel surface was polished using non-fluoridated pumice and water. The teeth were thoroughly rinsed under running water and then dabbed dry. Each premolar was covered in adhesive tape leaving the buccal surface of the crown uncovered, and then was immersed in Ten Cate demineralizing solution $^{23}$ ( $\mathrm{pH} 4.5$ ) for 96 hours. The adhesive tape was removed and the teeth were thoroughly washed under running water.

The teeth were numbered, and a random number generator (Urbaniak, G. C., \& Plous, S. (2013). Research Randomizer Version (4.0) was used to assign the teeth into 3 groups of 12 each.

Group I: (Zinc carbonate-n-HA)

Each tooth was treated daily with Biorepair tooth paste (Coswell S.p.A., Bologna, Italy) slurry applied with a soft toothbrush then returned to its container. The specimens were left in contact with the slurry for $3 \mathrm{~min}$.

\section{Group II: (CPP-ACP)}

Each tooth was treated daily with GC Tooth Mousse topical creme (GC Corporation, Tokyo, Japan). A sufficient amount of GC Tooth Mousse was applied to the tooth surface using a soft toothbrush and it was left undisturbed for 3 minutes. Then the tooth was returned to its container without rinsing.

Group III: (control group)

The teeth did not receive any further treatment.

Each group of teeth was stored in artificial saliva solution at $\mathrm{pH} 7$ in a separate container for the rest of the experimental period. The artificial saliva solution in each container was changed daily, $30 \mathrm{~min}$ after returning the teeth into the container. The treatment was carried out for a period of 28 days. 
Egyptian

Orthodontic Journal

Ten additional premolars were immersed in the demineralizing solution for 96 hours, followed by sectioning of these premolars and measurement of the lesion depth using polarized light microscopy (PLM) in order to establish the baseline lesion depth for comparison purposes.

\section{Polarized light microscopy}

The teeth were ground longitudinally in a buccolingual direction using a diamond disk under water cooling and then were further ground to reduce their thickness to $100 \mu \mathrm{m}$ using progressively finer grades of aluminum oxide wet sandpaper. The sections were then washed with deionized water and mounted on glass slides. All the sections were then examined using the polarized light microscope (Orthoplan, Leitz, Wetzlar, Germany) and photographed with 40X magnification. The enamel surface and the full depth of the lesion, which showed positive birefringence, were traced using a computer software program (Microsoft Office PowerPoint 2013, Microsoft Corporation, Redmond, Washington). Three vertical lines were drawn perpendicular to the enamel surface and they were extended to the deepest points of the lesion. (Figure 1) The three lines were measured for each sample using a computer software program (AutoCAD 2014 software, Autodesk, Inc., San Rafael, California). The three depth measurements for each lesion were then averaged to give the mean lesion depth for that lesion. The lesion depth was calculated in millimeters using a 1:40 scale and then converted into micrometers by multiplying it by $10^{3}$.

\section{Statistical analysis:}

The statistical analysis for this study was performed using Statistical Package for Social Sciences software version 20 (SPSS Inc, Chicago, Ill).

\section{RESULTS}

\section{1- Histological evaluation using the PLM pictures}

All the sections displayed increased birefringence (double refraction) of the enamel when examined under the PLM. The positively birefringent zone was located beneath a narrow negatively birefringent surface layer. 


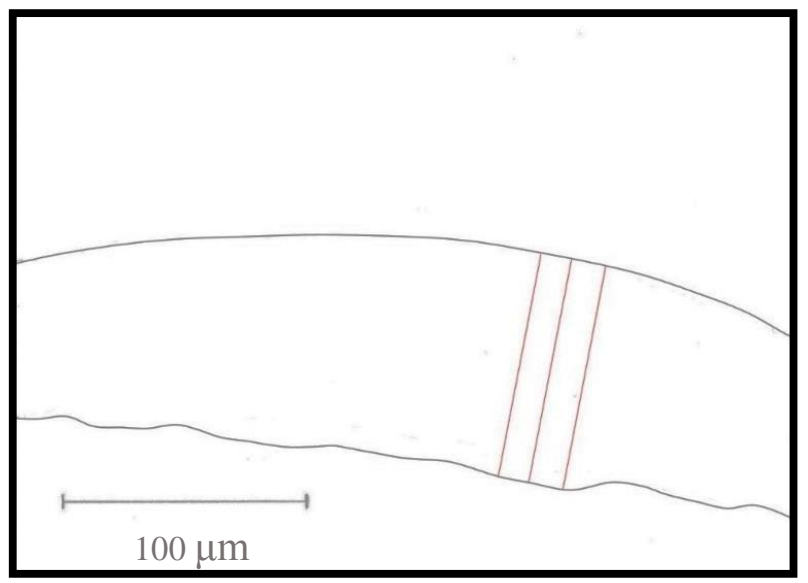

Figure 1. Tracing of a PLM picture of subsurface enamel lesion with the three depth measurement lines in red.

\section{a) Group I:}

Sections of the n-HA group showed areas of normal enamel birefringence extending between areas of increased birefringence of the lesions. In addition, they showed more superficial merge of the subsurface lesions with the normal enamel compared to the other groups. (Figure 2)

\section{a) Group II:}

Lesions observed in sections of the CPP-ACP group showed areas of increased birefringence which appeared less homogeneous than the control group. (Figure 3)

\section{a) Group III:}

The positively birefringent zone in the sections of the control group appeared more homogenous than the other two groups, and was covered by a thin negatively birefringent surface layer. The lesions extended deep into the enamel layer before merging with the normal birefringence of intact enamel. (Figure 4) 


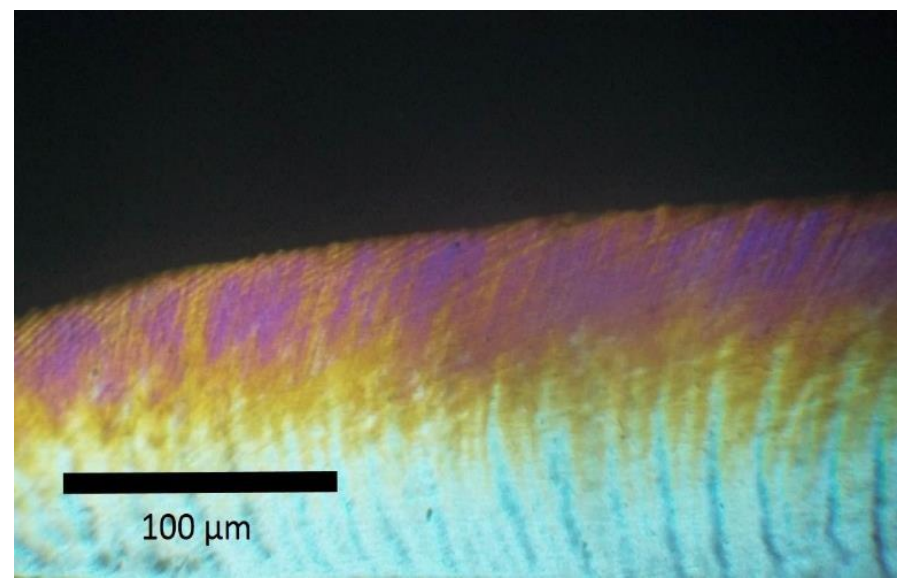

Figure 2. PLM picture of a section in the Biorepair group showing areas of normal enamel birefringence extending between areas of increased birefringence of the lesion.

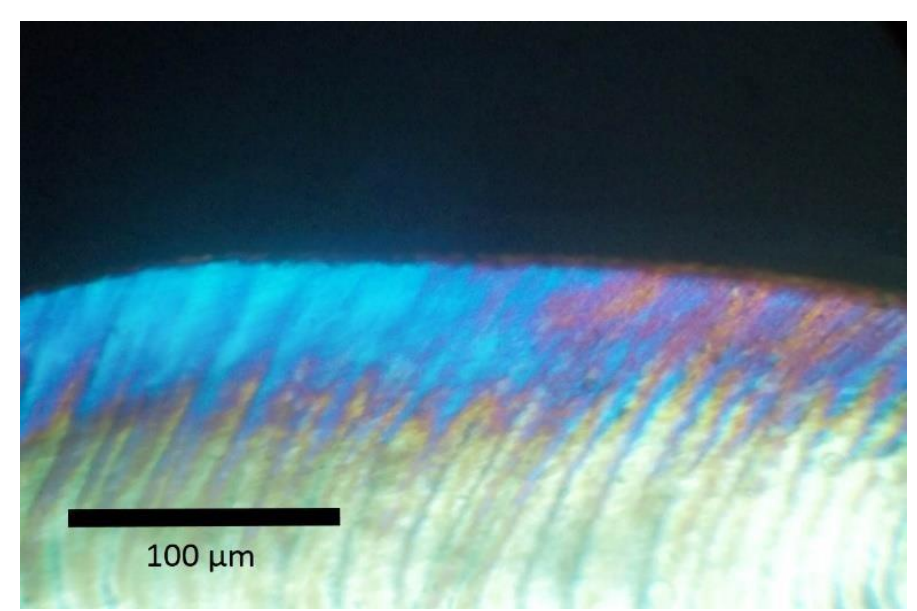

Figure 3. PLM picture of a section in the Tooth Mousse group showing less homogenous areas of increased birefringence.

\section{2- Evaluation of the depth of demineralized lesions}

The mean lesion depth ( \pm SD) following demineralization for 96 hours at $\mathrm{pH} 4.4$ was found to be $109.1 \pm 9.0 \mu \mathrm{m}$ and it ranged from 98.0 to $122.0 \mu \mathrm{m}$. 


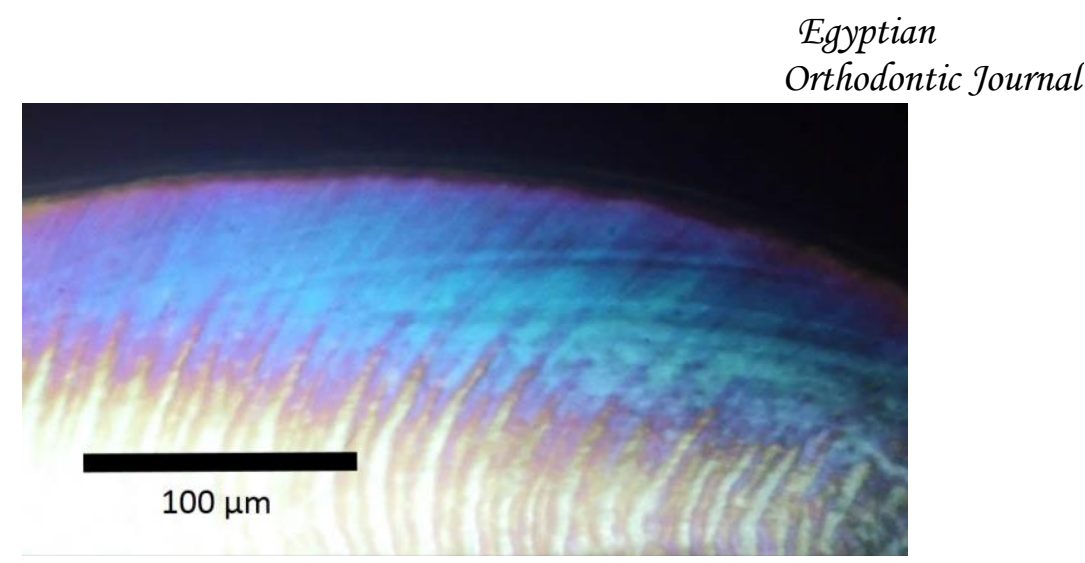

Figure 4. PLM picture of a section in the control group showing positive birefringence exending deep into the enamel before merging with normal enamel birefringence.

A comparison of the mean depths of demineralization in $\mu \mathrm{m}$ among the three groups is shown in Table 1. The control group showed the deepest lesions followed by the CPP-ACP group. Whereas the n-HA group showed the smallest lesion depth. The three groups showed a statistically significant difference $(p<0.001)$. The Post Hoc test showed a significant difference between the control group and the other test groups, but no difference was found between the n-HA group and the CPP-ACP group.

Table 1. Comparison of the mean lesion depth in $\mu \mathrm{m}$ among the study groups.

\begin{tabular}{|l|c|c|c|}
\hline \multicolumn{1}{|c|}{ Group } & $\begin{array}{c}\text { Group I } \\
(\mathbf{n = 1 2})\end{array}$ & $\begin{array}{c}\text { Group II } \\
(\mathbf{n = 1 2})\end{array}$ & $\begin{array}{c}\text { Group III } \\
(\mathbf{n = 1 2})\end{array}$ \\
\hline Min. - Max. & $61.0-90.0$ & $69.0-94.0$ & $93.0-120.0$ \\
\hline Mean \pm SD. & $76.8 \pm 10.2$ & $79.8 \pm 9.7$ & $107.8 \pm 8.5$ \\
\hline Median & 78.0 & 78.0 & 108.50 \\
\hline F & \multicolumn{3}{|c|}{$39.004^{*}$} \\
$P$ & $p_{1}=0.432, p_{2}<0.001^{*}, p_{3}<0.001^{*}$ \\
\hline Significance \\
between groups
\end{tabular}

F: F test (ANOVA)

Post Hoc test (LSD) was used for the comparison between groups

$p_{1}: p$ value for comparing between group I and group II

$p_{2}: p$ value for comparing between group I and group III

$p_{3}: p$ value for comparing between group II and group III

*: Statistically significant at $p \leq 0.05$

Volume 48 - December 2015 
Egyptian

Orthodontic Journal

\section{DISCUSSION}

Treatment with fixed orthodontic appliances has been reported to increase the prevalence of WSLs on the labial and buccal surfaces of teeth despite the use of prophylactic measures. ${ }^{24}$ The presence of such white lesions at the time of debonding can reduce the patient's satisfaction with the treatment results considering that patients usually seek orthodontic treatment to improve esthetics. ${ }^{25,26}$

The potential of fluoride to act as a remineralizaing agent was shown in previous studies. ${ }^{5-8,10}$ However, although fluoride treatment may arrest lesion progression, WSLs remain clinically visible, therefore, Øgaard et $\mathrm{al}^{27}$ recommended that WSLs should not be treated with concentrated fluorides.

The use of CPP-ACP in the current study was based upon the positive results demonstrated in previous studies that investigated the effect of different CPP-ACP formulations on the treatment of WSLs. ${ }^{714-16,28}$ The current study aimed to further investigate the effect of $\mathrm{CPP}-\mathrm{ACP}$ and to compare it to n-HA regarding their effects on the enamel lesion depth.

Artificially induced WSLs were used to study the remineralization of enamel owing to their histological similarity to natural WSLs. ${ }^{29,30}$ The method of production of WSLs was verified by subjecting 10 additional premolars to the demineralizing solution for 96 hours followed by sectioning of the teeth and examination of the sections using PLM. All the sections showed subsurface enamel lesions. In addition, the lesion depth for each of the ten samples was measured, allowing the establishment of baseline lesion depth measurements for comparison purposes.

A constant remineralization model was used to evaluate and compare the two tested materials. This model simulates a best-case scenario and allows initial screening of new products. . $^{31,32,32}$

Subsurface enamel lesions were obtained after demineralization; and they could be observed as a thin negatively birefringent surface zone on top of a positively birefringent body of the lesion. The initial depth of the demineralized lesions ranged from 98.0 to $122.0 \mu \mathrm{m}$ which was in accordance with Itthagarun et al. ${ }^{33}$ 


\section{Egyptian \\ Orthodontic Journal}

The lesions treated with n-HA group showed areas of normal birefringence extending between positively birefringent areas. This reduction in birefringence represents a decrease in porosity and hence indicates remineralization. ${ }^{34}$ The control group showed homogeneous positive birefringence extending deep into the enamel layer, indicating increased enamel porosity and accordingly implying demineralization of enamel.

The control group showed the largest mean lesion depth $(107.8 \mu \mathrm{m})$, while the smallest lesion depth was shown in the n-HA group $(76.8 \mu \mathrm{m})$. The CPP-ACP group showed a lesion depth of $79.8 \mu \mathrm{m}$ which was not significantly different from the n-HA group $(p=0.432)$.

The findings obtained in the study by Kumar et $\mathrm{al}^{16}$, support the remineralizing effect of CPP-ACP that was shown in the current study. They showed that a significant decrease in lesion depth was obtained after treatment of the demineralized enamel with CPP-ACP in the form of toothpaste or topical coating, while lesion depth increased in the negative control group. However, their mean lesion depth after treatment with CPP-ACP topical coating $(150.3 \mu \mathrm{m})$ was higher than the mean depth obtained in the current study for the CPP-ACP group $(79.8 \mu \mathrm{m})$. This may be the result of having deeper initial lesions than the current study, and subjecting their samples to $\mathrm{pH}$ cycling. The proposed mechanism of action of CPP-ACP is that it provides high concentrations of calcium and phosphate ions, which can then diffuse through the porous carious surface enamel into the subsurface body of the lesion. ${ }^{35}$ The high concentrations of calcium and phosphate ions are maintained during remineralization through the reservoir of bound ACP.

Similarly, the results of the study conducted by Itthagarun et $\mathrm{al}^{33}$ are in line with those of the current study regarding the remineralizing effect of n-HA. In their study, the n-HA toothpaste significantly decreased the mean depth of the lesions after treatment, while the negative control group showed a significant increase compared with the baseline values. It was suggested that n-HA particles penetrate the enamel pores and act as a template that continuously attracts calcium and phosphate ions from 


\begin{abstract}
Egyptian
Orthodontic Journal

the remineralizing solution, hence promoting enamel crystal growth. ${ }^{22}$

On the other hand, Comar et $\mathrm{al}^{36}$ showed in their study that treatment with n-HA or CPP-ACP pastes did not show a significant reduction of subsurface enamel demineralization compared with the control. This contradicts the results obtained in the current study, which demonstrated that both n-HA and CPP-ACP had a significant potential for the reduction of lesion depth compared with the control. The contradiction between the results might arise from the different methodologies employed. First, the assessment method was different. In their study, the subsurface demineralization was analyzed using cross-sectional hardness measured with knoop diamond tester; while in the current study the subsurface demineralization was assessed using PLM. In addition, Bovine enamel specimens were used in their study, while in the current study intact human premolars were used. The rate of lesion progression is faster in bovine enamel than in human enamel. ${ }^{37}$ Furthermore, the specimens in their study were subjected to $\mathrm{pH}$ cycling, which might have favored the process of demineralization and hindered remineralization.
\end{abstract}

\title{
CONCLUSIONS
}

1. Both n-HA and CPP-ACP resulted in a significant decrease in the depth of enamel lesions compared with the control.

2. There was no significant difference between n-HA and CPP-ACP regarding their effect on depth of enamel demineralization.

\section{REFERENCES}

1. Gwinnett AJ, Ceen RF. Plaque distribution on bonded brackets: a scanning microscope study. Am J Orthod. 1979;75(6):667-77.

2. Øgaard B, Rølla G, Arends J. Orthodontic appliances and enamel demineralization: Part 1. Lesion development. Am J Orthod Dentofacial Orthop. 1988;94(1):68-73. 
Egyptian

Orthodontic Journal

3. Sukontapatipark W, el-Agroudi MA, Selliseth NJ, Thunold K, Selvig KA. Bacterial colonization associated with fixed orthodontic appliances. A scanning electron microscopy study. Eur J Orthod. 2001;23(5):475-84.

4. Manji F, Fejerskov O, Nagelkerke N, Baelum V. A random effects model for some epidemiological features of dental caries. Community Dent Oral Epidemiol. 1991;19(6):324-8.

5. Ballard RW, Hagan JL, Phaup AN, Sarkar N, Townsend JA, Armbruster PC. Evaluation of 3 commercially available materials for resolution of white spot lesions. Am J Orthod Dentofacial Orthop. 2013;143(4):S78-S84.

6. Akin M, Basciftci FA. Can white spot lesions be treated effectively? Angle Orthod. 2012;82(5):770-5.

7. Ali PNM. Study of the effect of topically applied oral gel formulas in the prevention and treatment of early enamel decalcification (In vitro study). Department of Orthodontics, Alexandria University; 2007.

8. Kitasako Y, Tanaka M, Sadr A, Hamba H, Ikeda M, Tagami J. Effects of a chewing gum containing phosphoryl oligosaccharides of calcium (POs-Ca) and fluoride on remineralization and crystallization of enamel subsurface lesions in situ. $J$ Dent. 2011;39(11):771-9.

9. Baeshen HA, Lingström P, Birkhed D. Effect of fluoridated chewing sticks (Miswaks) on white spot lesions in postorthodontic patients. Am J Orthod Dentofacial Orthop. 2011;140(3):291-7.

10. Abdel-Haffiez SH. Study of the effect of a filled fluoride-releasing enamel sealant versus fluoride varnish on enamel demineralization. Department of Orthodontics, Alexandria university; 2011.

11. Larsen MJ, Fejerskov O. Chemical and structural challenges in remineralization of dental enamel lesions. Scand J Dent Res. 1989;97(4):285-96. 


\section{Egyptian \\ Orthodontic Journal}

12. Cochrane N, Cai F, Huq N, Burrow M, Reynolds E. New approaches to enhanced remineralization of tooth enamel. J Dent Res. 2010;89(11):1187-97.

13. Bergstrand F, Twetman S. A Review on Prevention and Treatment of Post-Orthodontic White Spot Lesions-Evidence-Based Methods and Emerging Technologies. Open Dent J. 2011;5:158-62.

14. Shen P, Cai F, Nowicki A, Vincent J, Reynolds E. Remineralization of enamel subsurface lesions by sugar-free chewing gum containing casein phosphopeptide-amorphous calcium phosphate. J Dent Res. 2001;80(12):2066-70.

15. Walker G, Cai F, Shen P, Bailey D, Yuan Y, Cochrane N, et al. Consumption of milk with added casein phosphopeptide-amorphous calcium phosphate remineralizes enamel subsurface lesions in situ. Australian dental journal. Wiley Online Library; 2009;54(3):245-9.

16. Kumar V, Itthagarun A, King N. The effect of casein phosphopeptide-amorphous calcium phosphate on remineralization of artificial caries-like lesions: an in vitro study. Aust Dent J. 2008;53(1):34-40.

17. Hannig M, Hannig C. Nanomaterials in preventive dentistry. Nat Nanotechnol. 2010;5(8):565-9.

18. Kani T, Kani M, Isozaki A, Kato H, Fukuoka Y, Ohashi T, et al. The effect to apatite-containing dentifrices on artificial caries lesions. J Dent Health. 1988;38(3):364-5.

19. Kani T, Kani M, Isozaki A, Shintani H, Ohashi T, Tokumoto T. Effect of apatite-containing dentifrices on dental caries in school children. J Dent Health. 1989;39:104-9.

20. Li L, Pan H, Tao J, Xu X, Mao C, Gu X, et al. Repair of enamel by using hydroxyapatite nanoparticles as the building blocks. J Mater Chem. 2008;18(34):4079-84.

21. Roveri N, Battistella E, Foltran I, Foresti E, Iafisco M, Lelli M, et al. Synthetic biomimetic carbonate-hydroxyapatite nanocrystals for enamel remineralization. Adv Mat Res. 2008;47:821-4. 
22. Huang S, Gao S, Yu H. Effect of nano-hydroxyapatite concentration on remineralization of initial enamel lesion in vitro. Biomed Mater. 2009;4(3):034104.

23. Ten Cate J, Duijsters P. Alternating demineralization and remineralization of artificial enamel lesions. Caries Res. 1982;16(3):201-10.

24. Hadler-Olsen S, Sandvik K, El-Agroudi MA, Øgaard B. The incidence of caries and white spot lesions in orthodontically treated adolescents with a comprehensive caries prophylactic regimen-a prospective study. Eur J Orthod. 2012;34(5):633-9.

25. Pabari S, Moles DR, Cunningham SJ. Assessment of motivation and psychological characteristics of adult orthodontic patients. Am J Orthod Dentofacial Orthop. 2011;140(6):e263-e272.

26. Samsonyanová L, Broukal Z. A systematic review of individual motivational factors in orthodontic treatment: facial attractiveness as the main motivational factor in orthodontic treatment. Int J Dent. 2014;2014:938274.

27. Øgaard B, Rølla G, Arends J, Ten Cate J. Orthodontic appliances and enamel demineralization Part 2. Prevention and treatment of lesions. Am J Orthod Dentofacial Orthop. 1988;94(2):123-8.

28. Elshafei AE. Evaluation of three different techniques in prevention and treatment of early enamel decalcification. Department of Orthodontics, Alexandria University; 2008.

29. Coolidge T, Besic F, Jacobs M. A microscopic comparison of clinically and artificially produced changes in enamel. Oral Surg Oral Med Oral Pathol. 1955;8(11):1204-10.

30. Soni NN, Brudevold F. Microradiographic and polarized-light studies of artificially produced lesions. J Dent Res.1960;39(2):233-40.

31. Tschoppe P, Zandim DL, Martus P, Kielbassa AM. Enamel and dentine remineralization by nano-hydroxyapatite toothpastes. J Dent. 2011;39(6):430-7. 
Egyptian

Orthodontic Journal

32. Kielbassa AM, Tschoppe P, Hellwig E, Wrbas KT. Effects of regular and whitening dentifrices on remineralization of bovine enamel in vitro. Quintessence Int. 2009;40(2):103-12.

33. Itthagarun A, King NM, Cheung Y-M. The effect of nanohydroxyapatite toothpaste on artificial enamel carious lesion progression: an in-vitro $\mathrm{pH}$-cycling study. Hong Kong Dent J. 2010;7(2):61-6.

34. Silverstone LM. Remineralization of human enamel in vitro. Proc roy Soc Med. 1972;65(10):906-8.

35. Reynolds E. Remineralization of enamel subsurface lesions by casein phosphopeptide-stabilized calcium phosphate solutions. J Dent Res. 1997;76(9):1587-95.

36. Comar LP, Souza BM, Gracindo LF, Buzalaf MA, Magalhães AC. Impact of Experimental Nano-HAP Pastes on Bovine Enamel and Dentin Submitted to a pH Cycling Model. Braz Dent J. 2013;24(3):273-8.

37. Featherstone J, Mellberg J. Relative rates of progress of artificial carious lesions in bovine, ovine and human enamel. Caries Res. 1981;15(1):109-14. 